\title{
Electrochemical Impedance Spectroscopy and Potentiodynamic Polarization Analysis on Anticorrosive Activity of Thiophene-2-Carbaldehyde Derivative in Acid Medium
}

\author{
Nimmy Kuriakose, Joby Thomas Kakkassery, Vinod P. Raphael, and Shaju K. Shanmughan \\ Research Division, Department of Chemistry, St.Thomas' College University of Calicut Thrissur, Kerala 680001, India \\ Correspondence should be addressed to Joby Thomas Kakkassery; drjobythomask@gmail.com
}

Received 18 September 2013; Accepted 16 December 2013; Published 2 February 2014

Academic Editors: A. Chatterji and A. M. Stephan

Copyright (C) 2014 Nimmy Kuriakose et al. This is an open access article distributed under the Creative Commons Attribution License, which permits unrestricted use, distribution, and reproduction in any medium, provided the original work is properly cited.

\begin{abstract}
The corrosion inhibition efficiency of thiophene-2-carbaldehyde tryptophan (T2CTRY) on mild steel (MS) in $1 \mathrm{M} \mathrm{HCl}$ solution has been investigated and compared using weight loss measurements, electrochemical impedance spectroscopy, and potentiodynamic polarization analysis. The Schiff base exhibited very good corrosion inhibition on mild steel in $\mathrm{HCl}$ medium and the inhibition efficiency increased with the increase in concentration of the inhibitor. The adsorption of the inhibitor on the surface of the corroding metal obeys Freundlich isotherm. Thermodynamic parameters $\left(\mathrm{K}_{\mathrm{ads}}, \Delta \mathrm{G}_{\mathrm{ads}}^{0}\right)$ were calculated using adsorption isotherm. Polarization studies revealed that T2CTRY acts as a mixed type inhibitor. A maximum of $96.2 \%$ inhibition efficiency was achieved by EIS studies at a concentration of $1 \mathrm{mM}$.
\end{abstract}

\section{Introduction}

Several Schiff bases were tested as corrosion inhibitors and it is reported that converting an amino compound into Schiff base increases the inhibition efficiency. Due to the presence of $\mathrm{C}=\mathrm{N}$ - group and electronegative $\mathrm{N}, \mathrm{S}$, or $\mathrm{O}$ atoms in the molecule, Schiff bases should be good corrosion inhibitors [14]. The action of such inhibitors depends on the specific interaction between the functional groups and the metal surface. Corrosion commonly occurs at metal surfaces in the presence of oxygen and moisture, involving electrochemical reactions [5-7]. The application of Schiff bases as an effective corrosion inhibitor is mainly based on their ability to form a monolayer on the surface of the corroding material.Increasing efforts have been made to study the corrosion behaviour of metals and mechanism of inhibition during the past decade mainly through electrochemical investigations [8-11].

The present investigation was undertaken to examine the corrosion inhibition behaviour of a novel heterocyclic Schiff base T2CTRY, derived from thiophene-2-carbaldehyde and tryptophan, in $1 \mathrm{M} \mathrm{HCl}$ solution on MS. The anticorrosive activity of this compound was evaluated by weight loss measurements, electrochemical impedance spectroscopy (EIS), and potentiodynamic polarization analysis.

\section{Experimental}

2.1. Inhibitor. Heterocyclic Schiff base T2CTRY was synthesized by the condensation of equimolar mixture of thiophene2-carbaldehyde and tryptophan in ethanol medium. The reaction mixture was refluxed for 3 hours, concentrated, and cooled. The yellow coloured solid was filtered, washed, and dried. Figure 1 shows the molecular structure of the heterocyclic Schiff base T2CTRY. Anal. calcd. for $\mathrm{C}_{16} \mathrm{H}_{14} \mathrm{~N}_{2} \mathrm{O}_{2} \mathrm{~S}$ : C, 64.43; H, 4.69; N, 9.39; O, 10.74; S, 10.74\%. Found.C, 63.98; H, 4.87; N, 9.12; O, 11.09; S, 10.21\%. IR (KBr): $v_{\mathrm{C}=\mathrm{N}}$ $1559 \mathrm{~cm}^{-1},{ }^{1} \mathrm{Hnmr}: \delta_{\mathrm{COOH}} 12.6, \delta_{\mathrm{CH}=\mathrm{N}} 9.84,{ }^{13} \mathrm{Cnmr}: \delta_{\mathrm{COOH}}$ $183.58, \delta_{\mathrm{CH}=\mathrm{N}} 132.4$. 


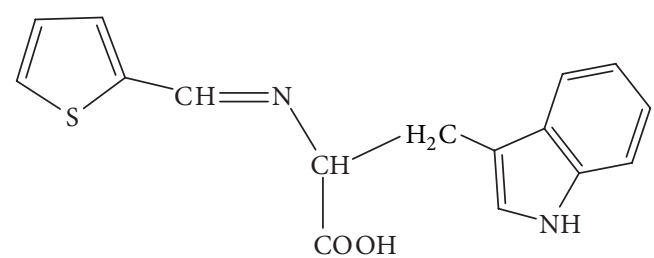

FIGURE 1: Molecular Structure of T2CTRY.

2.2. Solution. The aggressive solution of $1 \mathrm{M} \mathrm{HCl}$ was prepared by dilution of A.R grade $37 \%$ of $\mathrm{HCl}$ (Merck) with deionized water. Inhibitor solutions were prepared in the range $0.1 \mathrm{mM}-1 \mathrm{mM}$ concentrations.

2.3. Weight Loss Measurements. Mild steel (MS) specimens of dimension $1.5 \times 2 \times 0.1 \mathrm{~cm}$ were cut and abraded with various grades of silicon carbide papers $(200,400,600,800,1000$, 1200 , and 2000). The exact area and thickness of each coupon were measured and washed. Specimens were then degreased with acetone and finally dried. After weighing, specimens were separately immersed in $50 \mathrm{ml} 1 \mathrm{M} \mathrm{HCl}$ solution at $28^{\circ} \mathrm{C}$ in the absence and presence of the inhibitor T2CTRY. Weight loss of metal specimens was noted at every $24 \mathrm{~h}$ time interval for five days. The experiments were carried out in duplicate and the average values were reported. The corrosion rate $(\nu)$ is calculated by the following equation $[12,13]$ :

$$
v=\frac{W}{S t},
$$

where $W$ is the average weight loss of coupon, $S$ is the total area of specimen, and $t$ is the time of treatment. The percentage of inhibition efficiency $(\eta)$ can be calculated by the following equation:

$$
\eta_{w} \%=\frac{\nu_{0}-\nu}{\nu_{0}} \times 100,
$$

where $v_{0}$ and $v$ are the corrosion rates of uninhibited and inhibited specimens, respectively.

2.4. Electrochemical Impedance Spectroscopy (EIS). The EIS measurements were performed in a three electrode assembly. Saturated calomel electrode (SCE) was used as the reference electrode. Platinum electrode having $1 \mathrm{~cm}^{2}$ area was taken as counter electrode. Metal specimens with an exposed area of $1 \mathrm{~cm}^{2}$ were used as the working electrode. The EIS experiments were carried out on an Ivium compactstat-e electrochemical system. $1 \mathrm{M} \mathrm{HCl}$ was taken as the electrolyte and the working area of the metal specimens were exposed to the electrolyte for $1 \mathrm{~h}$ prior to the measurement. EIS measurements were performed at constant potential (OCP) in the frequency range from $1 \mathrm{KHz}$ to $100 \mathrm{mHz}$ with amplitude of $10 \mathrm{mV}$ as excitation signal. The percentages of inhibitions from impedance measurements were calculated using charge transfer resistance values by the following expression [1]:

$$
\eta_{\mathrm{EIS}} \%=\frac{R_{\mathrm{ct}}-R_{\mathrm{ct}}^{\prime}}{R_{\mathrm{ct}}} \times 100,
$$

where $R_{\mathrm{ct}}$ and $R_{\mathrm{ct}}^{\prime}$ are the charge transfer resistances of working electrode with and without inhibitor, respectively.

2.5. Potentiodynamic Polarization. Electrochemical polarization studies were performed by recording anodic and cathodic potentiodynamic polarization curves. Polarization plots were obtained in the electrode potential range from -100 to $+100 \mathrm{mV}$ versus corrosion potential $\left(E_{\text {corr }}\right)$ at a scan rate of $1 \mathrm{mV} / \mathrm{sec}$. Tafel polarization analysis was done by extrapolating anodic and cathodic curves to the potential axis to obtain corrosion current densities $\left(I_{\text {corr }}\right)$. The percentage of inhibition efficiency $\left(\eta_{\text {pol }} \%\right)$ was evaluated from the measured $I_{\text {corr }}$ values using the following relation [14]:

$$
\eta_{\text {pol }} \%=\frac{I_{\text {corr }}-I_{\text {corr }}^{\prime}}{I_{\text {corr }}} \times 100,
$$

where $I_{\text {corr }}$ and $I_{\text {corr }}^{\prime}$ are the corrosion current densities of the exposed area of the working electrode in the absence and presence of inhibitor, respectively. From the slope analysis of the linear polarization curves in the vicinity of corrosion potential of blank and different concentrations of the inhibitor, the values of polarization resistance $\left(R_{p}\right)$ in $1 \mathrm{M}$ $\mathrm{HCl}$ solution were obtained. From the evaluated polarization resistance, the inhibition efficiency was calculated using the relationship

$$
\eta_{R_{p}} \%=\frac{R_{p}^{\prime}-R_{p}}{R_{p}^{\prime}} \times 100,
$$

where $R_{p}^{\prime}$ and $R_{p}$ are the polarization resistance in the presence and absence of the inhibitor, respectively [1].

\section{Results and Discussions}

3.1. Weight Loss Measurements. The variation of corrosion rate and inhibition efficiency with immersion time was determined by weight loss measurements for a period of five days in the presence and absence of the Schiff base T2CTRY. From Table 1 it is clear that the rates of corrosion of the MS specimens decrease with increase in concentration of the T2CTRY while the percentage of inhibition is markedly increased with increasing the concentration which can be attributed to the increased adsorption of the T2CTRY molecules on the metal surface [14]. The increased surface coverage may partially hinder the reaction between metal and $\mathrm{H}^{+}$ions which in turn increase the percentage of inhibition. A maximum of $83.86 \%$ inhibition efficiency could be achieved by T2CTRY molecules at a concentration of $1.0 \mathrm{mM}$.

\subsection{Comparison of Inhibition Efficiency of Schiff Base with} Its Parent Amine. To compare the inhibition efficiencies of Schiff base and parent amine, weight loss measurements of MS specimens with parent amine tryptophan were performed in $1 \mathrm{M} \mathrm{HCl}$ at $28^{\circ} \mathrm{C}$ and the data is represented in Table 1. The inhibition efficiency of the Schiff base T2CTRY was markedly higher than that of the parent amine, for the studied concentrations. This investigation clearly establishes the role 


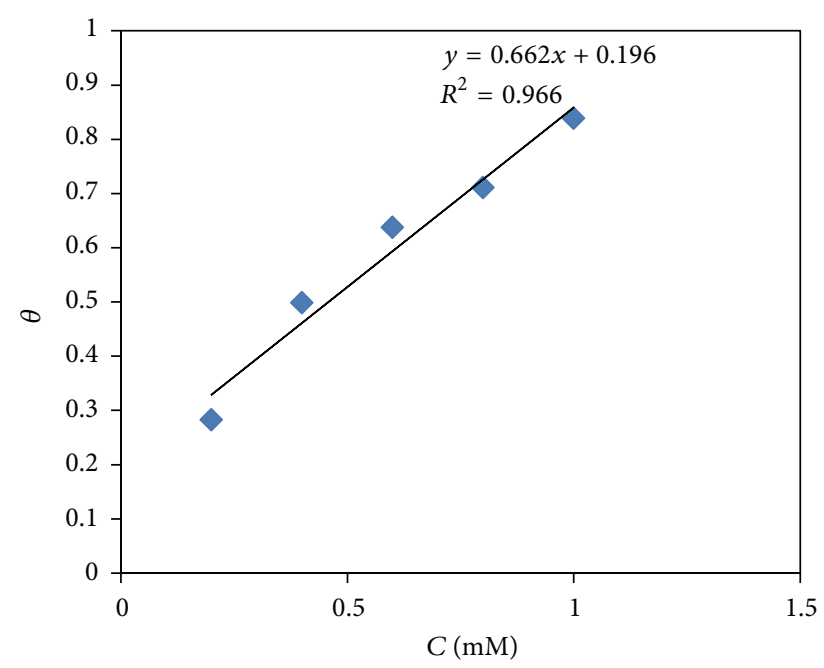

FIGURE 2: Freundlich adsorption isotherm for T2CTRY on MS surface in $1 \mathrm{M} \mathrm{HCl}$ at $28^{\circ} \mathrm{C}$.

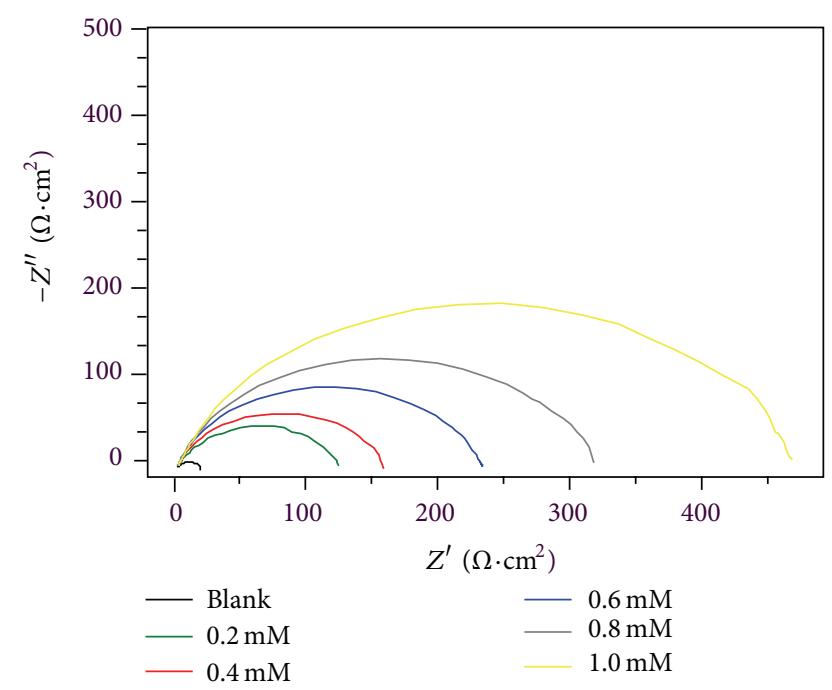

FIGURE 3: Nyquist plots for MS specimens in the presence and absence of T2CTRY.

TABLE 1: The corrosion rate and percentage of inhibition efficiencies of T2CTRY and tryptophan for MS specimens immersed in $1 \mathrm{M} \mathrm{HCl}$ at $28^{\circ} \mathrm{C}$ for $24 \mathrm{~h}$.

\begin{tabular}{lcccc}
\hline $\begin{array}{l}\text { Conc. } \\
(\mathrm{mM})\end{array}$ & \multicolumn{2}{c}{ T2CTRY } & \multicolumn{2}{c}{ Tryptophan } \\
& $\nu\left(\mathrm{mmy}^{-1}\right)$ & $\eta_{w} \%$ & $\nu\left(\mathrm{mmy}^{-1}\right)$ & $\eta_{w} \%$ \\
\hline 0 & 5.93 & - & & \\
0.2 & 4.26 & 28.26 & 4.61 & 22.30 \\
0.4 & 2.98 & 49.82 & & \\
0.6 & 2.15 & 63.75 & 3.02 & 49.25 \\
0.8 & 1.72 & 71.09 & & \\
1.0 & 0.96 & 83.86 & 2.29 & 61.66 \\
\hline
\end{tabular}

of azomethine linkage $(\mathrm{C}=\mathrm{N})$ present in the Schiff base which actively participates in the corrosion inhibition mechanism.
TABLE 2: Electrochemical impedance parameters of MS specimens in $1 \mathrm{M} \mathrm{HCl}$ in the absence and presence of T2CTRY.

\begin{tabular}{lccc}
\hline Conc. $(\mathrm{mM})$ & $R_{\mathrm{ct}}\left(\Omega \mathrm{cm}^{2}\right)$ & $\mathrm{CPE}\left(\mu \mathrm{Fcm}^{-2}\right)$ & $\eta_{\mathrm{EIS}} \%$ \\
\hline 0 & 16.4 & 95.8 & - \\
0.2 & 109 & 82.3 & 84.9 \\
0.4 & 142 & 77.0 & 88.5 \\
0.6 & 211 & 75.5 & 92.2 \\
0.8 & 286 & 68.3 & 94.3 \\
1.0 & 427 & 64.6 & 96.2 \\
\hline
\end{tabular}

3.3. Adsorption Isotherm and Free Energy of Adsorption. The mechanism of adsorption and the surface behaviour of organic molecules can be easily viewed through adsorption isotherms. Different models of adsorption isotherms considered are Langmiur, Temkin, Frumkin, and Freundlich isotherms. For the evaluation of thermodynamic parameters, it is necessary to determine the best fit isotherm with the aid of correlation coefficient $\left(R^{2}\right)$. The best fit adsorption isotherm for the adsorption of T2CTRY on MS specimens in $1 \mathrm{M} \mathrm{HCl}$ was Freundlich adsorption isotherm which can be expressed as

$$
\theta=K_{\text {ads }} C,
$$

where $C$ is the concentration of the inhibitor, $\theta$ is the fractional surface coverage, and $K_{\text {ads }}$ is the adsorption equilibrium constant [15]. Figure 2 represents the Freundlich adsorption isotherm for T2CTRY and the $K_{\text {ads }}$ is related to the standard free energy of adsorption $\Delta G_{\text {ads }}^{0}$, by

$$
G_{\mathrm{ads}}^{0}=-\mathrm{RT} \ln \left(55.5 K_{\mathrm{ads}}\right),
$$

where 55.5 is the molar concentration of water, $R$ is the universal gas constant and $T$ is the temperature in Kelvin [16]. The negative value of free energy of adsorption indicates the spontaneity of the process. In the present investigation T2CTRY molecules showed $\Delta G_{\text {ads }}^{0}=-32.07 \mathrm{~kJ} / \mathrm{mol}$ suggesting that the adsorption involves both physisorption and chemisorption [17].

3.4. Electrochemical Impedance Spectroscopy. Figures 3 and 4 represent the Nyquist and Bode plots of MS specimens in $1 \mathrm{M} \mathrm{HCl}$. It is evident from the plots that the impedance response of metal specimens showed a marked difference in the presence and absence of the inhibitor T2CTRY. The capacitance loop intersects the real axis at higher and lower frequencies. At high frequency end, the intercept corresponds to the solution resistance $\left(R_{s}\right)$ and at lower frequency end, the intercept corresponds to the sum of $R_{s}$ and charge transfer resistance $\left(R_{\mathrm{ct}}\right)$. The difference between the two values gives $R_{\mathrm{ct}}$ [18-20]. The value of $R_{\mathrm{ct}}$ is a measure of electron transfer across the exposed area of the metal surface and it is inversely proportional to rate of corrosion [21-23].

Impedance behavior can be well explained by pure electric models that could verify and enable to calculate numerical values corresponding to the physical and chemical properties of electrochemical system under examination. The 
TABLE 3: Potentiodynamic polarization parameters of $\mathrm{MS}$ specimens in $1 \mathrm{M} \mathrm{HCl}$ at $28^{\circ} \mathrm{C}$ in the absence and presence of T2CTRY.

\begin{tabular}{|c|c|c|c|c|c|c|c|}
\hline \multicolumn{5}{|c|}{ Tafel data } & \multicolumn{3}{|c|}{ Linear polarization data } \\
\hline Conc. (mM) & $E_{\text {corr }}(\mathrm{mV} / \mathrm{SCE})$ & $I_{\text {corr }}\left(\mu \mathrm{A} / \mathrm{cm}^{2}\right)$ & $b_{a}(\mathrm{mV} / \mathrm{dec})$ & $-b_{c}(\mathrm{mV} / \mathrm{dec})$ & $\eta_{\mathrm{pol}} \%$ & $R_{p}(\mathrm{ohm})$ & $\eta_{R_{p}} \%$ \\
\hline 0 & -465 & 726 & 72 & 106 & - & 21.8 & - \\
\hline 0.2 & -479 & 141 & 79 & 97 & 80.58 & 113.5 & 80.79 \\
\hline 0.4 & -476 & 94.6 & 87 & 83 & 86.96 & 194 & 88.76 \\
\hline 0.6 & -485 & 53.6 & 78 & 85 & 92.62 & 278 & 92.16 \\
\hline 0.8 & -476 & 42.4 & 72 & 83 & 94.16 & 313 & 93.04 \\
\hline 1.0 & -495 & 34.1 & 89 & 87 & 95.30 & 459 & 95.25 \\
\hline
\end{tabular}

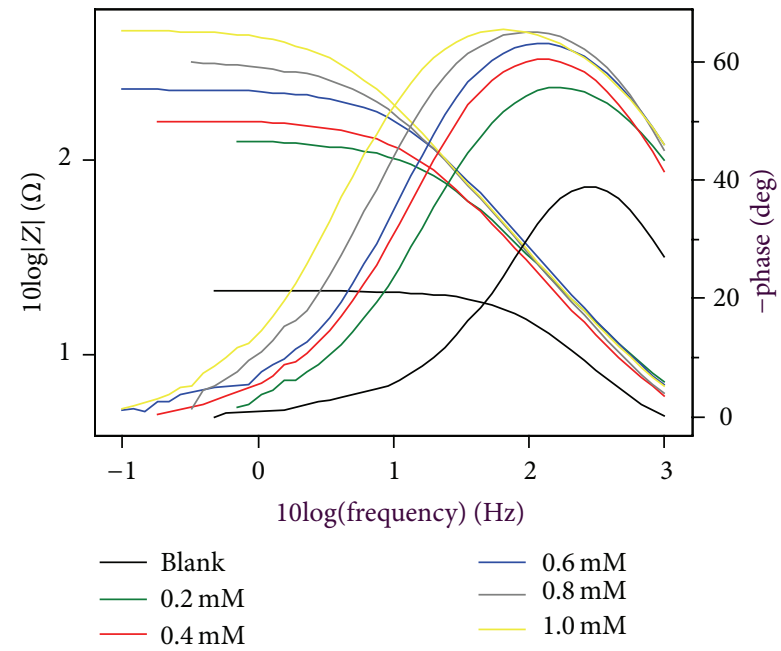

FIGURE 4: Bode plots for MS specimens in the presence and absence of T2CTRY.

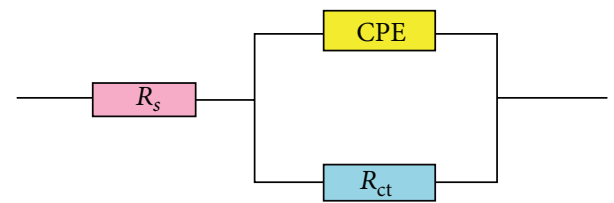

FIGURE 5: Equivalent circuit fitting for EIS measurements.

simple equivalent circuit that fits to many electrochemical system composed of a double layer capacitance, $R_{s}$ and $R_{\mathrm{ct}}$ $[24,25]$. To reduce the effects due to surface irregularities of metal, constant phase element (CPE) is introduced into the circuit instead of a pure double layer capacitance [26] which gives more accurate fit as shown in the Figure 5.

The impedance of CPE can be expressed as

$$
Z_{\mathrm{CPE}}=\frac{1}{Y_{0}(j \omega)^{n}},
$$

where $Y_{0}$ is the magnitude of CPE, $n$ is the exponent (phase shift), $\omega$ is the angular frequency, and $j$ is the imaginary unit. CPE may be resistance, capacitance, and inductance depending upon the values of $n$ [27]. In all experiments, the observed value of $n$ ranges between 0.8 and 1.0, suggesting the capacitive response of CPE. The EIS parameters such as $R_{\mathrm{ct}}, R_{s}$, and $\mathrm{CPE}$ and the calculated values of

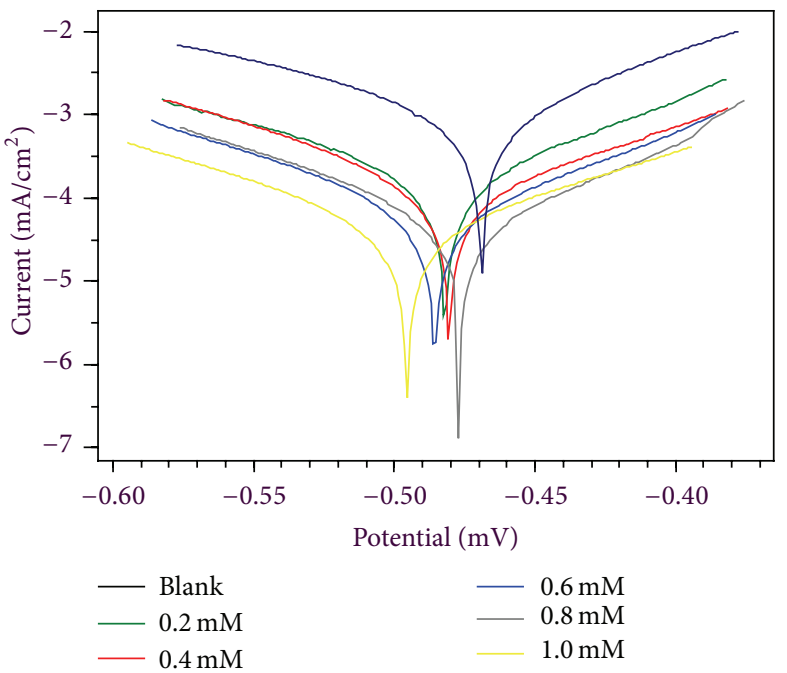

FIGURE 6: Tafel plots of MS Specimens with and without inhibitor T2CTRY.

percentage of inhibition $\left(\eta_{\text {EIS\% }}\right)$ of MS specimens are listed in Table 2. The $R_{\mathrm{ct}}$ values are increased with increasing inhibitor concentration. Decrease in capacitance values CPE with inhibitor concentration can be attributed to the decrease in local dielectric constant and/or increase in the thickness of the electrical double layer. This emphasises the action of inhibitor molecules by adsorption at the metal-solution interface [28]. The percentage of inhibition $\left(\eta_{\text {EIS\% }}\right)$ showed a regular increase with increase in inhibitor concentration. A maximum of $96.2 \%$ inhibition efficiency could be achieved at an inhibitor concentration of $1 \mathrm{mM}$.

3.5. Potentiodynamic Polarization Studies. Potentiodynamic polarization curves for T2CTRY are shown in Figure 6. Polarization parameters like corrosion current densities $\left(I_{\text {corr }}\right)$, corrosion potential $\left(E_{\text {corr }}\right)$, cathodic Tafel slope $\left(b_{c}\right)$, anodic Tafel slope $\left(b_{a}\right)$, and inhibition efficiency $\left(E_{p}\right)$ for MS specimens are listed in Table 3. A prominent decrease in the corrosion current density $\left(I_{\text {corr }}\right)$ was observed in the presence of inhibitor T2CTRY. The lowest value of $I_{\text {corr }}$ was noticed for the inhibitor solution of concentration $1 \mathrm{mM}$ which exhibited a maximum inhibition efficiency of $95.3 \%$. Since the value of $b_{c}$ changes appreciably in the presence of T2CTRY, it may be assumed that the inhibitor molecules are more adsorbed 
on cathodic sites. Generally if the shift of $E_{\text {corr }}$ is $>85$ with respect to $E_{\text {corr }}$ of uninhibited solution, the inhibitor can be viewed as cathodic or anodic type [29]. In the present study the maximum shift of $E_{\text {corr }}$ is $30 \mathrm{mV}$, suggesting that T2CTRY acts as a mixed type inhibitor for MS specimens in $1 \mathrm{M} \mathrm{HCl}$ [30].

\section{Mechanism of Inhibition}

It is well known that the surface of the metal is positively charged in acidic media [3]. It is believed that the $\mathrm{Cl}^{-}$ ions could be specifically adsorbed on the metal surface and create an excess of negative charge on the surface. This will favour the adsorption of protonated Schiff base on the surface and hence reduce the dissolution of $\mathrm{Fe}$ to $\mathrm{Fe}^{2+}$ [29]. Besides this electrostatic interaction between the protonated Schiff base and the metal surface, other possible interactions are (i) interaction of unshared electron pairs in the molecule with the metal (ii) interaction of $\pi$-electrons with the metal and (iii) a combination of types ((i)-(ii)) [30, 31]. If one examines the structure of Schiff base (T2CTRY), many potential sources of inhibitor-metal-interaction can be recognized. The unshared pair of electrons present on $N$ atoms is of key importance in making coordinate bond with the metal. The $\pi$-electron cloud of the aromatic rings and the azomethine linkage also participate in the inhibition mechanism. Furthermore, the double bonds in the inhibitor molecule permit the back donation of metal d electrons to the $\pi^{*}$ orbital and this type of interaction cannot occur with amines [32]. This can be justified by the lower inhibition efficiency of the parent amine than that of Schiff base.

\section{Conclusions}

(1) T2CTRY is a good corrosion inhibitor for MS in $1 \mathrm{M} \mathrm{HCl}$. A maximum of $95 \%$ of inhibition efficiency could be achieved with this inhibitor by Tafel polarization studies.

(2) Compared to the parent amine, tryptophan, the Schiff base T2CTRY exhibited higher inhibition efficiencies for MS.

(3) Adsorption of the inhibitor T2CTRY on mild steel obeys Freundlich isotherm.

(4) The thermodynamic parameters of the adsorption are calculated from the adsorption isotherms which showed that both physisorption and chemisorption are involved in the inhibition process.

\section{Conflict of Interests}

The authors declare that there is no conflict of interests regarding the publication of this paper.

\section{References}

[1] A. Raman and P. Labine, Reviews on Corrosion Inhibitor Science and Technology, NACE, Houston, Tex, USA, 1986.
[2] F. Bentiss, M. Traisnel, L. Gengembre, and M. Lagrenée, "Inhibition of acidic corrosion of mild steel by 3,5-diphenyl-4H-1,2,4triazole," Applied Surface Science, vol. 161, no. 1-2, pp. 194-202, 2000.

[3] E. E. Oguzie, "Corrosion inhibition of mild steel in hydrochloric acid solution by methylene blue dye," Materials Letters, vol. 59, no. 8-9, pp. 1076-1079, 2005.

[4] A. Yurt and Ö. Aykin, "Diphenolic Schiff bases as corrosion inhibitors for aluminium in $0.1 \mathrm{M} \mathrm{HCl}$ : potentiodynamic polarisation and EQCM investigations," Corrosion Science, vol. 53, no. 11, pp. 3725-3732, 2011.

[5] X. Li, S. Deng, and H. Fu, "Blue tetrazolium as a novel corrosion inhibitor for cold rolled steel in sulfuric acid solution," Materials Chemistry and Physics, vol. 129, no. 3, pp. 696-700, 2011.

[6] M. Behpour, S. M. Ghoreishi, N. Soltani, M. Salavati-Niasari, M. Hamadanian, and A. Gandomi, "Electrochemical and theoretical investigation on the corrosion inhibition of mild steel by thiosalicylaldehyde derivatives in hydrochloric acid solution," Corrosion Science, vol. 50, no. 8, pp. 2172-2181, 2008.

[7] K. Stanly Jacob and G. Parameswaran, "Corrosion inhibition of mild steel in hydrochloric acid solution by Schiff base furoin thiosemicarbazone," Corrosion Science, vol. 52, no. 1, pp. 224$228,2010$.

[8] S. Deng, X. Li, and H. Fu, "Alizarin violet $3 \mathrm{~B}$ as a novel corrosion inhibitor for steel in $\mathrm{HCl}, \mathrm{H}_{2} \mathrm{SO}_{4}$ solutions," Corrosion Science, vol. 53, no. 11, pp. 3596-3602, 2011.

[9] A. Paul, K. Joby Thomas, V. P. Raphael, and K. S. Shaju, "Chelating efficacy and corrosion inhibition capacity of Schiff base derived from 3-formylindole," Oriental Journal of Chemistry, vol. 28, no. 3, pp. 1501-1507, 2012.

[10] V. P. Raphael, K. Joby Thomas, K. S. Shaju, and A. Aby Paul, "Corrosion inhibition investigations of 3-acetylpyridine semicarbazone on carbon steel in hydrochloric acid medium," Research on Chemical Intermediates, vol. 39, no. 2, 2013.

[11] T. A. Sethi, R. K. Upadhyay, A. Chaturvedi, and S. P. Mathur, "Corrosion inhibitory effects of some Schiff's bases on mild steel in acid media," Journal of the Chilean Chemical Society, vol. 52, no. 3, pp. 1206-1213, 2007.

[12] ASTM, AST G-31-72, Standard Recommended Practice for the Laboratory Immersion Corrosion Testing of Metals, American Society for Testing and Materials, Philadelphia, Pa, USA, 1990.

[13] K. C. Emregül and O. Atakol, "Corrosion inhibition of iron in $1 \mathrm{M} \mathrm{HCl}$ solution with Schiff base compounds and derivatives," Materials Chemistry and Physics, vol. 83, no. 2-3, pp. 373-379, 2004.

[14] I. B. Obot and N. O. Obi-Egbedi, "Adsorption properties and inhibition of mild steel corrosion in sulphuric acid solution by ketoconazole: experimental and theoretical investigation," Corrosion Science, vol. 52, no. 1, pp. 198-204, 2010.

[15] E. S. Ferreira, C. Giacomelli, F. C. Giacomelli, and A. Spinelli, "Evaluation of the inhibitor effect of L-ascorbic acid on the corrosion of mild steel," Materials Chemistry and Physics, vol. 83, no. 1, pp. 129-134, 2004.

[16] X. Li, S. Deng, and H. Fu, "Synergism between red tetrazolium and uracil on the corrosion of cold rolled steel in $\mathrm{H}_{2} \mathrm{SO}_{4}$ solution," Corrosion Science, vol. 51, no. 6, pp. 1344-1355, 2009.

[17] E. Cano, J. L. Polo, A. L. A. Iglesia, and J. M. Bastidas, "A study on the adsorption of benzotriazole on copper in hydrochloric acid using the inflection point of the isotherm," Adsorption, vol. 10, no. 3, pp. 219-225, 2004. 
[18] H. H. Hassan, E. Abdelghani, and M. A. Amin, "Inhibition of mild steel corrosion in hydrochloric acid solution by triazole derivatives. Part I. polarization and EIS studies," Electrochimica Acta, vol. 52, no. 22, pp. 6359-6366, 2007.

[19] F. Mansfeld, "Recording and analysis of AC impedance data for corrosion studies," Corrosion, vol. 37, no. 5, pp. 301-307, 1981.

[20] M. S. Abdel-Aal and M. S. Morad, "Inhibiting effects of some quinolines and organic phosphonium compounds on corrosion of mild steel in $3 \mathrm{M} \mathrm{HCl}$ solution and their adsorption characteristics," British Corrosion Journal, vol. 36, no. 4, pp. 253-260, 2001.

[21] P. Bommersbach, C. Alemany-Dumont, J. P. Millet, and B. Normand, "Formation and behaviour study of an environmentfriendly corrosion inhibitor by electrochemical methods," Electrochimica Acta, vol. 51, no. 6, pp. 1076-1084, 2005.

[22] I. L. Rosenfield, Corrosion Inhibitors, McGraw-Hill, New York, NY, USA, 1981.

[23] M. El Azhar, B. Mernari, M. Traisnel, F. Bentiss, and M. Lagrenée, "Corrosion inhibition of mild steel by the new class of inhibitors [2,5-bis(n-pyridyl)-1,3,4-thiadiazoles] in acidic media," Corrosion Science, vol. 43, no. 12, pp. 2229-2238, 2001.

[24] A. Yurt, A. Balaban, S. U. Kandemir, G. Bereket, and B. Erk, "Investigation on some Schiff bases as $\mathrm{HCl}$ corrosion inhibitors for carbon steel," Materials Chemistry and Physics, vol. 85, no. 2-3, pp. 420-426, 2004.

[25] A. K. Singh, S. K. Shukla, M. Singh, and M. A. Quraishi, "Inhibitive effect of ceftazidime on corrosion of mild steel in hydrochloric acid solution," Materials Chemistry and Physics, vol. 129, no. 1-2, pp. 68-76, 2011.

[26] E. McCafferty and N. Hackerman, "Double layer capacitance of iron and corrosion inhibition with polymethylene diamines," Journal of Electrochemical Society, vol. 119, no. 2, pp. 146-154, 1972.

[27] F. Bentiss, M. Lebrini, and M. Lagrenée, "Thermodynamic characterization of metal dissolution and inhibitor adsorption processes in mild steel/2,5-bis( $n$-thienyl)-1,3,4-thiadiazoles/ hydrochloric acid system," Corrosion Science, vol. 47, no. 12, pp. 2915-2931, 2005.

[28] W.-H. Li, Q. He, S.-T. Zhang, C.-L. Pei, and B.-R. Hou, "Some new triazole derivatives as inhibitors for mild steel corrosion in acidic medium," Journal of Applied Electrochemistry, vol. 38, no. 3, pp. 289-295, 2008.

[29] F. Bentiss, M. Traisnel, and M. Lagrenee, "The substituted 1,3,4oxadiazoles: a new class of corrosion inhibitors of mild steel in acidic media," Corrosion Science, vol. 42, no. 1, pp. 127-146, 2000.

[30] D. P. Schweinsberg, G. A. George, A. K. Nanayakkara, and D. A. Steinert, "The protective action of epoxy resins and curing agents-inhibitive effects on the aqueous acid corrosion of iron and steel," Corrosion Science, vol. 28, no. 1, pp. 33-42, 1988.

[31] H. Shokry, M. Yuasa, I. Sekine, R. M. Issa, H. Y. El-Baradie, and G. K. Gomma, "Corrosion inhibition of mild steel by Schiff base compounds in various aqueous solutions: part 1," Corrosion Science, vol. 40, no. 12, pp. 2173-2186, 1998.

[32] A. K. Singh and M. A. Quraishi, "Inhibiting effects of 5-substituted isatin-based Mannich bases on the corrosion of mild steel in hydrochloric acid solution," Journal of Applied Electrochemistry, vol. 40, no. 7, pp. 1293-1306, 2010. 

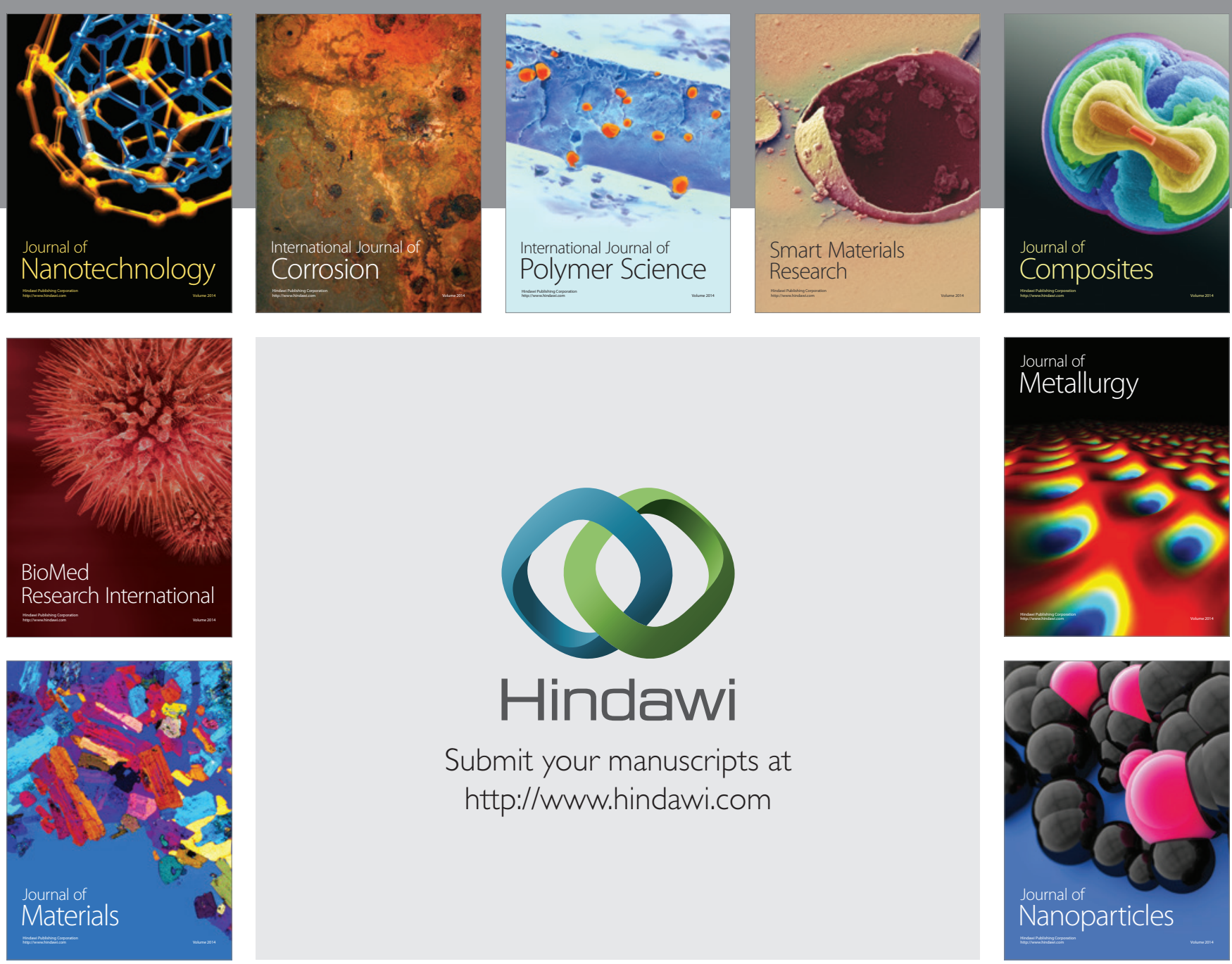

Submit your manuscripts at http://www.hindawi.com
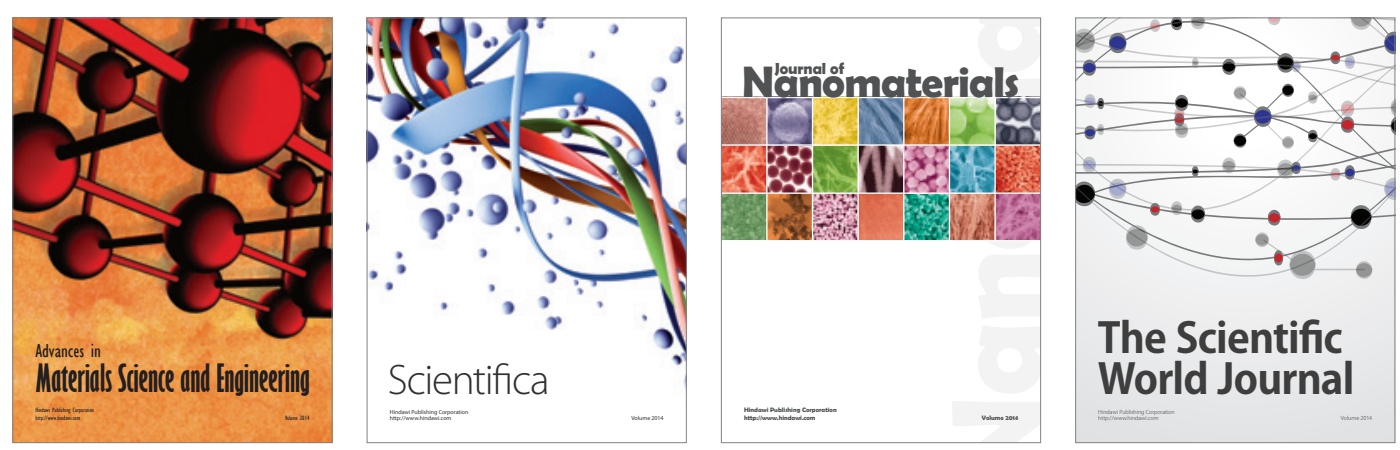

\section{The Scientific World Journal}
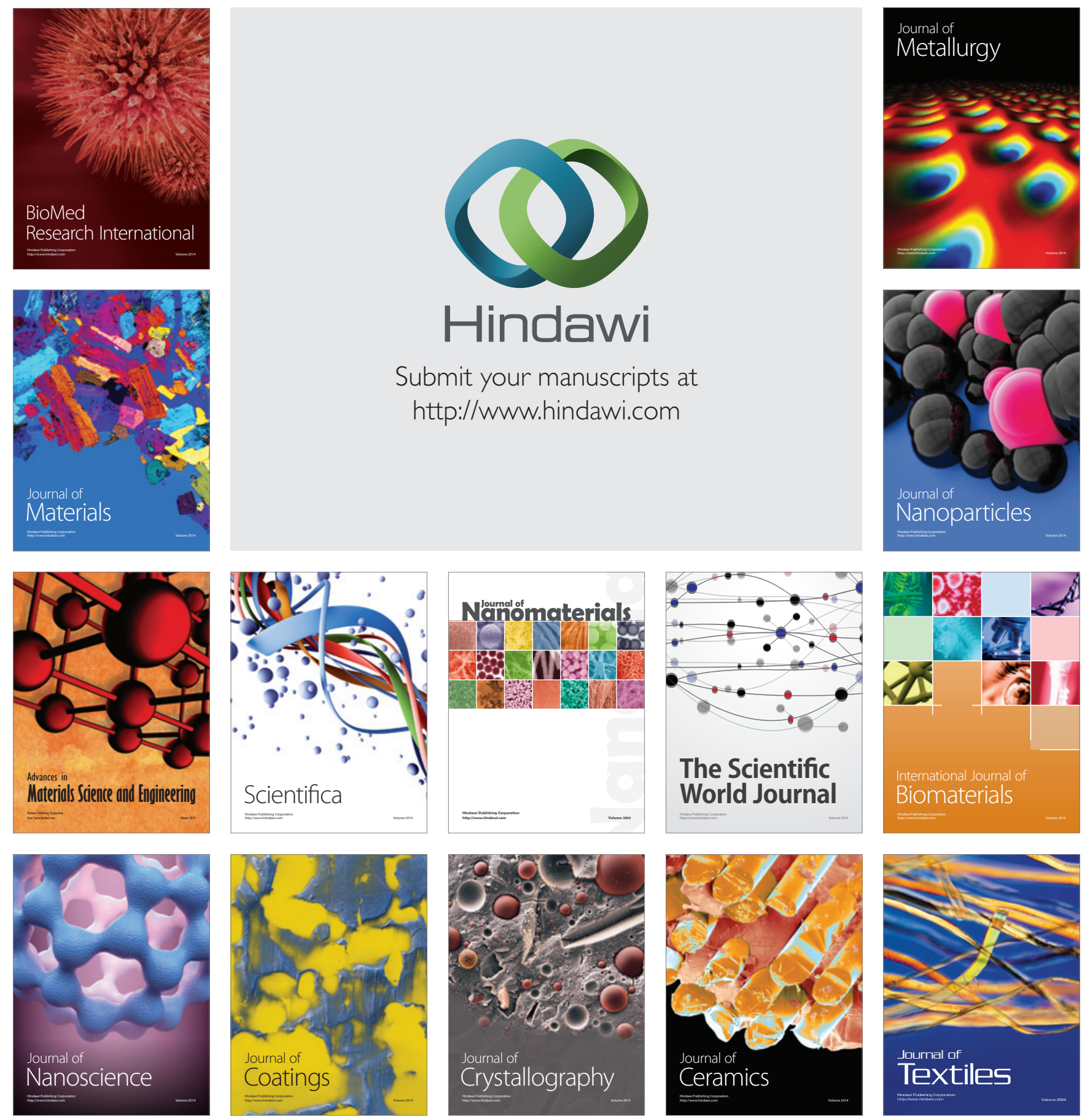